\title{
Regulation of Transepithelial Ion Transport in the Rat Late Distal Colon by the Sympathetic Nervous System
}

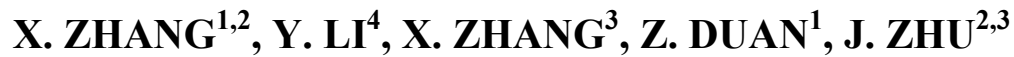 \\ ${ }^{1}$ Artificial Liver Center, Beijing Youan Hospital, Capital Medical University, Beijing, China, ${ }^{2}$ Key \\ Laboratory for Medical Tissue Regeneration of Henan Province, School of Basic Medical Sciences, \\ Xinxiang Medical University, Xinxiang, China, ${ }^{3}$ Department of Physiology and Pathophysiology, \\ School of Basic Medical Sciences, Capital Medical University, Beijing, China, ${ }^{4}$ Department of \\ Immunology, School of Basic Medical Sciences, Capital Medical University, Beijing, China
}

Received April 1, 2014

Accepted June 10, 2014

On-line September 5, 2014

\begin{abstract}
Summary
The colorectum (late distal colon) is innervated by the sympathetic nervous system, and many colorectal diseases are related to disorders of the sympathetic nervous system. The sympathetic regulation of colorectal ion transport is rarely reported. The present study aims to investigate the effect of norepinephrine (NE) in the normal and catecholamine-depleted condition to clarify the regulation of the sympathetic adrenergic system in ion transport in the rat colorectum. NE-induced ion transport in the rats colorectum was measured by short-circuit current $\left(I_{\mathrm{sc}}\right)$ recording; the expression of $\beta$-adrenoceptors and NE transporter (NET) were quantified by real-time PCR, and western blotting. When the endogenous catecholamine was depleted by reserpine, the baseline $I_{\mathrm{sc}}$ in the colorectum was increased significantly comparing to controls. NE evoked downward $\Delta I_{\text {sc }}$ in colorectum of treated rats was 1.8 -fold of controls. The expression of $\beta_{2}$-adrenoceptor protein in the colorectal mucosa was greater than the control, though the mRNA level was reduced. However, NET expression was significantly lower in catecholamine-depleted rats compared to the controls. In conclusion, the sympathetic nervous system plays an important role in regulating basal ion transport in the colorectum. Disorders of sympathetic neurotransmitters result in abnormal ion transport, $\beta$-adrenoceptor and NET are involved in the process.
\end{abstract}

\section{Key words}

Sympathetic nervous system • Colorectum • Ion transport

\section{Corresponding authors}

J. Zhu, Key Laboratory for Medical Tissue Regeneration of Henan Province, School of Basic Medical Sciences, Xinxiang Medical University, Xinxiang, Henan, China. E-mail: zhu_jx@ccmu.edu.cn or/and Z. Duan, Artificial Liver Center, Beijing Youan Hospital, Capital Medical University, Beijing, China. E-mail: duan2517@163.com

\section{Introduction}

The late distal colon (colorectum) is the terminal region of the intestine, and performs the functions of water absorption and feces expulsion. Involuntary control of the colon and rectum is regulated by the sympathetic nervous system (Ridolfi et al. 2009), through neurons with cell bodies that lie within the dorsal horn of the lumbar spinal cord (T5-L2) (Winge et al. 2003). Sympathetic nerve fibers enter the intestinal wall along arteries and terminate in the myenteric and submucosal plexuses and in the mucosa. They control motility, secretion and vasoregulation (Straub et al. 2006). The sympathetic regulation of colorectal motility has been demonstrated (Ridolfi et al. 2009), but the regulation of colorectal ion transport remains vague.

Neurotransmitters of the sympathetic nerve terminal are ligands at functional receptors to perform biological functions. Norepinephrine (NE) and epinephrine are the active biogenic amines of the sympathoadrenal system and have strong and wide

PHYSIOLOGICAL RESEARCH • ISSN 0862-8408 (print) • ISSN 1802-9973 (online)

(c) 2015 Institute of Physiology v.v.i., Academy of Sciences of the Czech Republic, Prague, Czech Republic

Fax +420 241062 164, e-mail: physres@biomed.cas.cz, www.biomed.cas.cz/physiolres 
participation in the regulation and control of many physiological functions. In any particular tissue, the content of NE reflects sympathetic innervation (MartínezOlivares et al. 2006). NE has been reported to promote $\mathrm{Na}^{+}, \mathrm{Cl}^{-}$, water absorption in both small intestine and colon (Tapper et al. 1981), and evoke $\mathrm{K}^{+}$secretion in the rat colon (Schultheiss and Diener 2000). Although epinephrine is a sympathetic neurotransmitter, the necessary concentration to induce maximal secretion is most likely never observed in vivo, when the hormone is secreted from adrenal gland, reaching the gut via the circulation (Schultheiss and Diener 2000). When NE is released from sympathetic nerve endings within the intestinal wall, it may reach much higher local concentrations. Therefore, the aim of the present study was to investigate the secretory effect of $\mathrm{NE}$ in rats with and without reserpine-induced chemical sympathectomy to clarify the regulation of the sympathetic adrenergic system in colorectal ion transport.

\section{Materials and Methods}

\section{Tissue preparation}

All experiments used male Sprague-Dawley rats (200-250 g) maintained in the animal care facility at the Laboratory Animal Services Center of Capital Medical University. The procedure was approved by the Beijing Administrative Office of Laboratory Animals, in accordance with the Administrative Regulations on Laboratory Animals of Beijing Municipality. The rats had free access to water and food until the day of the experiment. The rats were killed by cervical dislocation. The colorectal segment $(1 \mathrm{~cm})$ approximately $2-3 \mathrm{~cm}$ away from the anus (around the lymph node) was quickly removed and placed in Krebs-Hensleit solution (K-HS). The serosa, muscularis propria and submucosa were stripped away by hand to obtain the mucosal preparation of the colorectum.

\section{Short-circuit current measurement and data evaluation}

Briefly, the tissue was fixed in a modified Ussing chamber with a cross sectional area of $0.5 \mathrm{~cm}^{2}$, bathed with a volume of $5 \mathrm{ml}$ on each side of the mucosa and short-circuited by a voltage clamp (Physiologic Instruments, San Diego, CA, USA) with a correction for the solution resistance. The short-circuit current $\left(I_{\mathrm{sc}}\right)$ was continuously recorded and tissue conductance was measured every minute. Drugs were added directly to the basolateral side of the epithelium. The change in $I_{\mathrm{sc}}\left(\Delta I_{\mathrm{sc}}\right)$ was calculated as the difference before and after adding drugs and was normalized to the current per unit area of epithelium ( $\left.\mu \mathrm{A} / \mathrm{cm}^{2}\right)$ (Zhang et al. 2008).

\section{Catecholamine depletion with reserpine}

Intraperitoneal injection of reserpine depletes endogenous catecholamines, producing a nonspecific temporary sympathectomy (Fleming et al. 1973). Rats were weighed and intraperitoneally administered with reserpine (Guangdong BangMin Pharmaceutical Co., Ltd, China) at a dose of $5 \mathrm{mg} / \mathrm{kg}$. Eighteen hours after the injection, rats were killed by cervical dislocation and the colorectum was rapidly removed and subjected to $I_{\mathrm{sc}}$ recording or $\beta$-adrenoceptor expression assays. Controls were intraperitoneally injected daily with sterile $0.9 \%$ saline $(1 \mathrm{ml})$.

\section{$R N A$ extraction and preparation of $c D N A$}

The mucosa of late distal colon was collected in PBS $(0.9 \% \mathrm{NaCl}$ in $0.01 \mathrm{M}$ sodium phosphate buffer, $\mathrm{pH} 7.4$ ), which had been treated with $0.1 \%$ diethyl pyrocarbonate (depc-PBS). The tissue was cleaned with depc-PBS and transferred to Trizol (Invitrogen) for extraction of total RNA, which was isolated according to the manufacturer's instructions and stored at $-80{ }^{\circ} \mathrm{C}$ for additional use. Samples of cDNA were generated by reverse transcription following the Superscript first-stand synthesis protocol for RT-PCR (Invitrogen).

\section{Real time polymerase chain reaction (Real-time PCR)}

Real-time PCR was used to quantify mRNA encoding $\beta_{1}-, \beta_{2}$-adrenoceptor and NE transporter (NET) in the colorectal mucosa. Expression of $\beta$-actin was used as an internal control for normalization. The specific primers are listed in Table 1. The adrenoceptor and NET transcript levels in the rat colorectal samples were comparatively quantified with the Brilliant SYBR Green QPCR Master Mix kit (Stratagene, La Jolla, CA, USA) using a Light Cycler instrument (Stratagene). Amplifications were performed in a final volume of $20 \mu \mathrm{l}$ of a commercial reaction mixture according to the manufacturer's instructions. Data were analyzed using the MxPro QPCR software (version 3.0, Mx3000P system, Stratagene).

\section{Western blotting analysis}

Tissues were harvested from the colorectal mucosa, washed with PBS, and homogenized in $300 \mu \mathrm{l}$ of cold lysis buffer containing Nonidet P-40 (1\%), Tris-HCl, (10 mM, pH 8.0), EDTA (1.0 mM), $\mathrm{NaCl}$ 
Table 1. Sequences of primers.

\begin{tabular}{|c|c|c|c|}
\hline Primers & $\begin{array}{c}\text { GenBank } \\
\text { accession number }\end{array}$ & Primer sequence & $\begin{array}{l}\text { Primer location } \\
\text { in the sequence }\end{array}$ \\
\hline \multirow[t]{2}{*}{$\beta$-actin } & NM031144 & F: 5'- TTC AAC ACC CCA GCC ATG T - 3' & $460-478$ \\
\hline & & R: 5'- GTG GTA CGA CCA GAG GCA TAC A -3' & $506-527$ \\
\hline \multirow[t]{2}{*}{$\beta_{1}$-adrenoceptor } & NM012701 & F: 5’-CAT CAT GGC CTT CGT GTA CCT-3' & $714-734$ \\
\hline & & R: 5'-TGT CGA TCT TCT TCA CCT GTT TCT-3' & $755-778$ \\
\hline \multirow[t]{2}{*}{$\beta_{2}$-adrenoceptor } & NM012492 & F: 5’-TTG CCA AGT TCG AGC GAC TAC-3’' & $372-392$ \\
\hline & & R: 5'-CAC ACG CCA AGG AGG TTA TGA-3' & $411-431$ \\
\hline \multirow[t]{2}{*}{$N E T$} & AB021971 & F: 5'- TGG CCA TGT TTT GCA TAA CG -3' & $193-222$ \\
\hline & & R: 5'- GCG AAG GTG TCC AGC AGA GT -3' & $167-186$ \\
\hline
\end{tabular}

Table 2. Antibody used in the study.

\begin{tabular}{|c|c|c|c|c|}
\hline Antibody & $\begin{array}{c}\text { Immunizing antigen or } \\
\text { conjugation }\end{array}$ & Host species & Dilution & Source/Catalog No. \\
\hline$\beta_{1}$-adrenoceptor & $\begin{array}{l}\text { a peptide mapping at c-terminus of } \\
\beta_{1} \text {-adrenoceptor of mouse origin }\end{array}$ & Rabbit & $1: 500$ & Santa Cruz / sc-568 \\
\hline$\beta_{2}$-adrenoceptor & $\begin{array}{l}\text { a peptide mapping at c-terminus of } \\
\beta_{2} \text {-adrenoceptor of mouse origin }\end{array}$ & Rabbit & $1: 500$ & Santa Cruz / sc-570 \\
\hline$N E T$ & $\begin{array}{l}22 \text { amino acid peptide sequence } \\
\text { mapping to the } 1^{\text {st }} \text { extracellular } \\
\text { domain of rat NET }\end{array}$ & Rabbit & $1: 500$ & Chemicon / AB5066P \\
\hline Actin & $\begin{array}{l}\text { a peptide corresponds to amino acid } \\
\text { resides } 20-33 \text { of actin with } \\
\text { N-terminal added lysine }\end{array}$ & Rabbit & $1: 10,000$ & Sigma / A5060 \\
\hline Goat anti-rabbit IgG & IRDye ${ }^{\mathrm{TM}} 800$ & Goat & $1: 10,000$ & Rockland / 611-132-122 \\
\hline
\end{tabular}

(150 mM), SDS (1\%), sodium orthovanadate $(1 \mathrm{mM})$, deoxycholic acid $(0.5 \%)$, phenylmethanesulfonyl fluoride (1.0 $\mathrm{mM})$, aprotinin $(5 \mu \mathrm{g} / \mathrm{ml})$, and leupeptin $(5 \mu \mathrm{g} / \mathrm{ml})$, all purchased from the Sigma Chemical Co. (St. Louis, MO, USA). The total tissue homogenates were sonicated to dissolve them completely and then centrifuged at $12,000 \mathrm{rpm}$ for $45 \mathrm{~min}$ at $4{ }^{\circ} \mathrm{C}$. The supernatant was collected. After SDS/PAGE on $10 \%$ gels, the proteins $(80 \mu \mathrm{g})$ were electroblotted onto a nitrocellulose (NC, Millipore) membrane for $20 \mathrm{~min}$ at $15 \mathrm{mV}$. To minimize non-specific protein binding, the NC membrane was treated with blocking buffer containing $5 \%$ non-fat dry milk in Tris-sodium chloride buffer (TBS, including $10 \mathrm{mM}$ Tris- $\mathrm{HCl}, 500 \mathrm{mM} \mathrm{NaCl}, \mathrm{pH} 7.5)$ for $1 \mathrm{~h}$ at room temperature. The blot was incubated overnight at $4{ }^{\circ} \mathrm{C}$ with polyclonal primary antibodies to the $\beta_{1}$ - or $\beta_{2}$-adrenoceptor or the NET. After a series of wash steps in TBST (TBS containing $0.05 \%$ Tween 20 ), the blot was incubated with a secondary antibody to rabbit $\mathrm{IgG}$ for $1 \mathrm{~h}$ at room temperature (Table 2). The blot was finally washed with TBS, scanned in the Odyssey Infrared Imager (LI-COR, Nebraska, USA), and analyzed with the Odyssey software package (version 1.2). Beta-actin was used as an internal control.

\section{Solutions and drugs}

The K-HS contained (mM): $\mathrm{NaCl} 117$, $\mathrm{KCl}$ 4.7, $\mathrm{NaHCO}_{3} 24.8, \mathrm{KH}_{2} \mathrm{PO}_{4} 1.2, \mathrm{MgCl}_{2} \cdot 6 \mathrm{H}_{2} \mathrm{O}$ 1.2, $\mathrm{CaCl}_{2} \cdot 2 \mathrm{H}_{2} \mathrm{O} 2.5$ and glucose 11.1 . The solution was gassed with a gas mixture of $5 \% \mathrm{CO}_{2}$ and $95 \% \mathrm{O}_{2}$. The $\mathrm{pH}$ was adjusted to 7.4 with $1 \mathrm{M} \mathrm{HCl}$. Indomethacin and dimethyl sulfoxide (DMSO) were obtained from Sigma. Stock solutions of indomethacin were dissolved in DMSO, with a final DMSO concentration that never exceeded $0.1 \%$ (vol/vol). Norepinephrine bitartrate was purchased from Jin Yao Amino Acids Pharmaceutical 
Co., Ltd (Tianjin, China).

\section{Statistics and data analysis}

Data are presented as the mean \pm SEM, $n$ refers to the number of rats per group. Statistical analyses were performed by one-way ANOVA followed by the Newman-Keuls test or Student's paired or unpaired t-test. Statistics and graphs were generated using GraphPad Prism, version 4.0 (GraphPad Software Inc., San Diego, CA, USA). $\quad \mathrm{P}<0.05$ was considered statistically significant.

\section{Results}

The regulation of ion transport in the rat colorectum by the sympathetic nervous system

After approximately $30 \mathrm{~min}$ of stabilization in the Ussing chamber with K-HS, indomethacin $(10 \mu \mathrm{M})$ was routinely added to the basolateral side to abolish the effects of endogenous prostaglandin (Zhang et al. 2008). The main neurotransmitter of the sympathetic nervous system, NE $(10 \mu \mathrm{M})$ evoked an $\Delta I_{\text {sc }}$ of $-30.1 \pm 3.8 \mu \mathrm{A} / \mathrm{cm}^{2}$ (Fig. 1B,C), suggesting that the sympathetic nervous system could regulate the transepithelial ion transport in rat colorectum.
Effect of catecholamine depletion on ion transport in the rat colorectum

To investigate the sympathetic regulation of ion transport in the colorectum, we used reserpine to exhaust the endogenous catecholamine stores and thus exclude the effects of the sympathetic nervous system. The reserpine-treated rats were feeble, and the feces were shapeless (Fig. 1A). The baseline $I_{\mathrm{sc}}$ in catecholaminedepleted rats was increased 2.8 -fold relative to the control $(\mathrm{n}=11, \mathrm{P}<0.05)$; the transepithelial resistance (Rte) was not significant altered (Table 3). The NE-induced $\Delta I_{\mathrm{sc}}$ was increased from $-30.3 \pm 1.6$ to $-54.4 \pm 4.6 \mu \mathrm{A} / \mathrm{cm}^{2}$ in catecholamine-depleted rats, which was 1.8 -fold higher than the control $(\mathrm{n}=4, \mathrm{P}<0.01)$ (Fig. 1B,C).

Table 3. The basic $I_{S C}$ values in the colorectal mucosa of rats.

\begin{tabular}{lccc}
\hline Group & $\mathbf{n}$ & $\begin{array}{c}\text { Basal } \boldsymbol{I}_{\boldsymbol{S C}} \\
\boldsymbol{\mu A} / \mathbf{c m}^{2}\end{array}$ & $\begin{array}{c}\text { Transepithelial } \\
\text { resistance (Rte) } \\
\mathbf{\Omega} \cdot \mathbf{c m}^{\mathbf{2}}\end{array}$ \\
\hline Control & 11 & $21.7 \pm 4.8$ & $78.2 \pm 12.0$ \\
Reserpine & 11 & $81.8 \pm 8.0 *$ & $72.9 \pm 8.2$ \\
\hline
\end{tabular}

Data are expressed as mean $\pm \mathrm{SEM} ; * \mathrm{P}<0.05$.
A

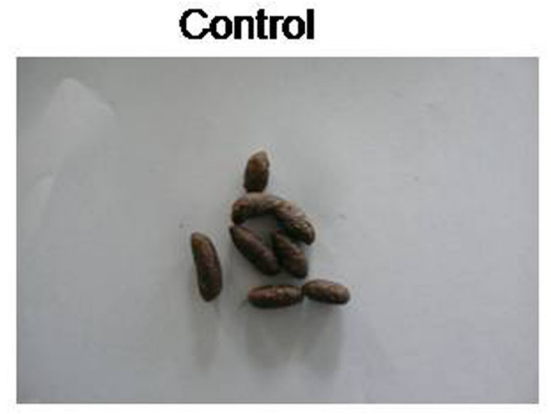

B

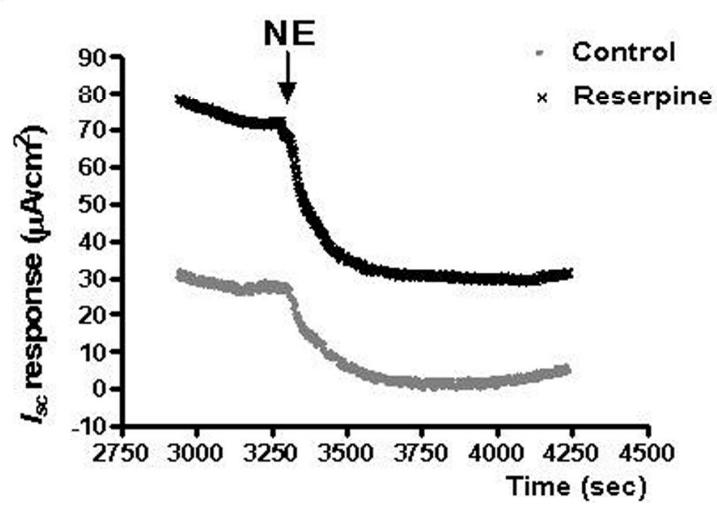

Reserpine

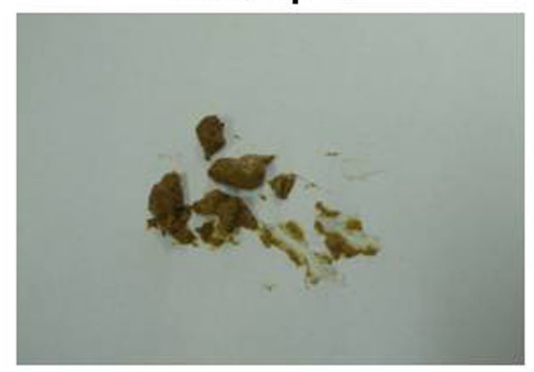

C

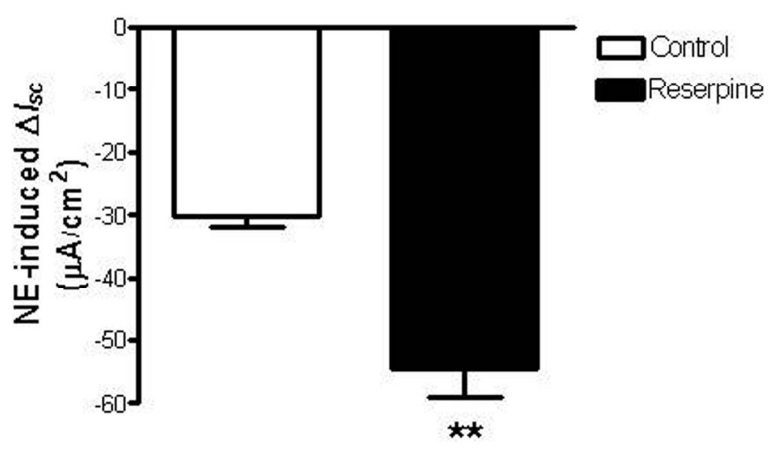

Fig. 1. NE-evoked ion transport in the mucosa of the late distal colon in control and reserpine-treated rats. A. Feces shapes in different rat groups. B, C. NE $(10 \mu \mathrm{M})$ induced Isc response in the colorectal mucosa of control and reserpine-treated rats $(n=11)$. Data are expressed as mean $\pm \mathrm{SEM} ; * * \mathrm{P}<0.01$. 

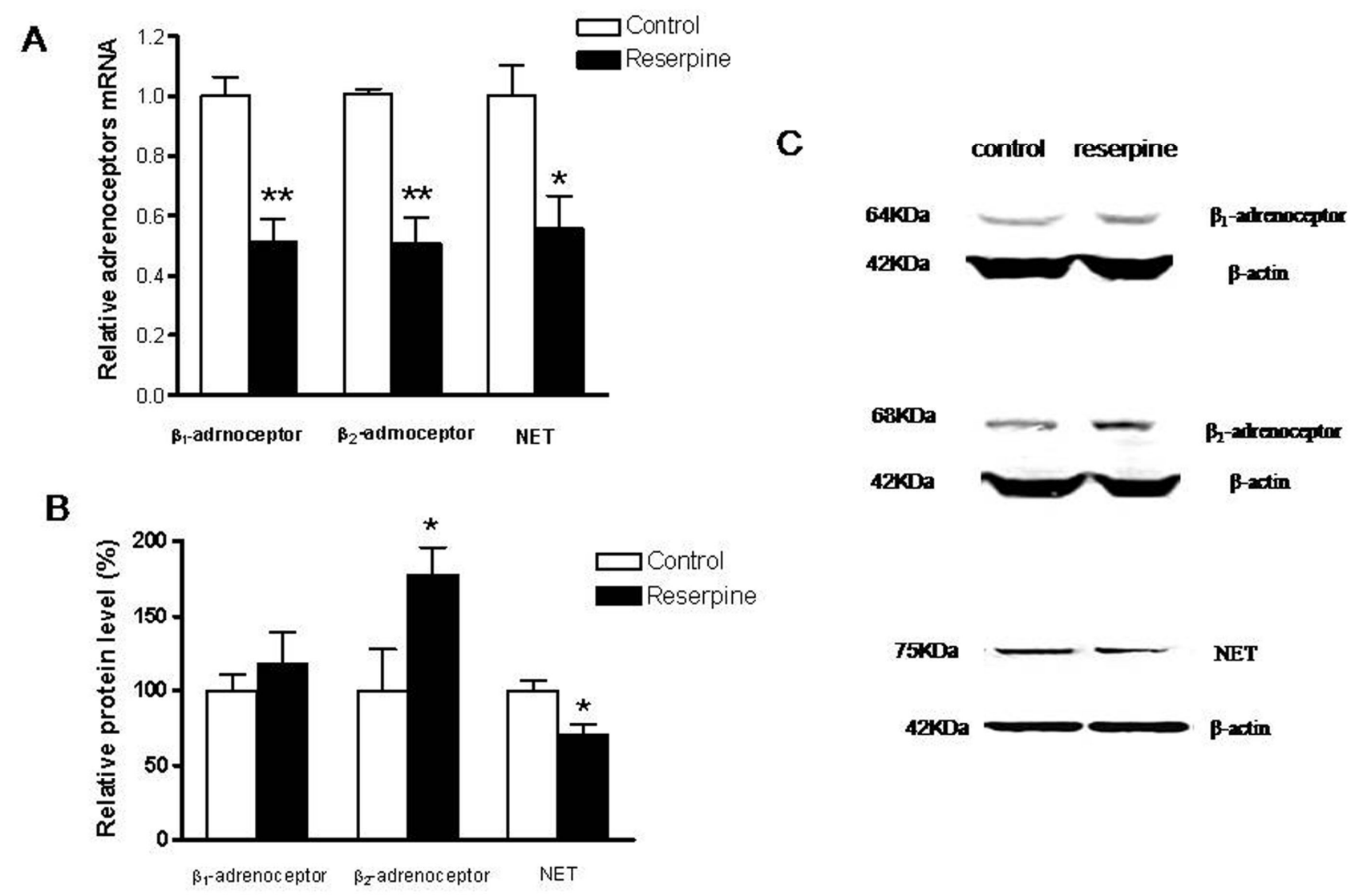

Fig. 2. $\beta$-adrenoceptor expression in the colorectal mucosa in control and reserpine-treated rats. A. The mRNA level of $\beta$-adrenoceptors and NETs in the colorectal mucosa of control and reserpine-treated rats. B, C. The protein level of $\beta$-adrenoceptors $(n=4)$ and NETs $(n=5)$ in the colorectal mucosa of control and reserpine-treated rats. $\beta$-actin was the internal control for normalization. Data are expressed as mean $\pm \mathrm{SEM} ; * \mathrm{P}<0.05 ; * * \mathrm{P}<0.01$.

Effects of catecholamine depletion on the expression of $\beta$-adrenoceptor and NET in colorectal mucosa

$\beta_{1^{-}}$and $\beta_{2}$-adrenoceptors were reported to mediate the effect of NE-induced ion transport in the colorectum (Zhang et al. 2008); therefore, to further investigate the sympathetic regulation of the colorectum, the expression of $\beta$-adrenoceptors was investigated in catecholamine-depleted rats. The $\beta_{1}$-adrenoceptor mRNA expression level was significantly decreased by $48.9 \%$ $(\mathrm{n}=4, \mathrm{P}<0.01) \quad$ (Fig. 2A), and no significant change was found in the protein level (Fig. 2B,C). The $\beta_{2}$-adrenoceptor mRNA expression level was decreased by $49.7 \%(n=4, P<0.01)$ (Fig. $2 A)$, but the protein level was increased $(n=4, P<0.05)$ (Fig. $2 B, C)$.

The NET reuptakes NE to repackage or metabolize, and supports efficient noradrenergic signaling and presynaptic NE homeostasis (Matthies et al. 2009), which is essential for phenotypic specification. It is a hallmark protein of noradrenergic neurons (Fan et al. 2009). Therefore, we examined the expression of NET in catecholamine-depleted rats. The NET mRNA level was reduced by $44.3 \%$ compared to the controls $(n=3$, $\mathrm{P}<0.05$ ) (Fig. 2A), and the protein level was also reduced by $22.5 \% \quad(n=5, P<0.05) \quad$ (Fig. $2 B, C)$. These results indicate that the sympathetic regulation is attenuated in the catecholamine-depleted colorectum.

\section{Discussion}

The present study investigates the regulation of ion transport by the sympathetic nervous system in the rat colorectum. The sympathetic nervous system regulates gastrointestinal blood flow, electrolyte transport, mucous secretion, and motility, among other aspects of physiology (Gershon and Erde 1981, Vanner and Surprenant 1996). The gut mucosa is extensively innervated by noradrenergic neurons and a high concentration of catecholamines can be potentially achieved in the vicinity of the epithelial cells (Gershon and Erde 1981). Under physiological conditions, the 
colonic mucosa close to the anus (colorectum) usually plays an important role in water and electrolyte absorption (Kunzelmann and Mall 2002); however, there are few studies reporting the regulation of colorectal ion transport by the sympathetic nervous system.

Sympathetic innervation regulates intestinal fluid and electrolyte transport by providing tonic inhibition of secretory fluxes and mediates a proabsorptive phenotype via adrenoceptors (Carey and Zafirova 1990). NE is a primary neurotransmitter of the sympathetic nervous system, and can evoke transepithelial ion flux in the rat colorectum via $\beta$-adrenoceptors located on the mucosa (Zhang et al. 2008, 2010). Thus, the effect of NE on colorectal secretion indirectly reflects extent of sympathetic nervous system innervation in the colorectum. Though NE induces ion transport in the rat distal colon, the effect of $\mathrm{NE}$ is larger in the colorectum than in other parts of distal colon (Zhang et al. 2010), indicating that sympathetic innervation in the colorectum is augmented compared to other parts of the colon. Liu et al. (1997) and Lam et al. (2003) found $\alpha_{2}$-adrenoceptor takes part in the intestinal ion transport. We previously have reported that $\alpha$-adrenoceptors are not involved in the ion transport induced by NE, as the antagonist of $\alpha$-adrenoceptor phentolamine did not block the $I_{\mathrm{sc}}$ invoked by NE (Zhang et al. 2010), which is different from theirs. The main reason might be the differential tissue preparations. The mucosa-only preparation was used in our study, but the mucosa-submucosa preparation was used in theirs. It has been reported that $\alpha_{2}$-adrenoceptors were more distributed in the submucosal plexus, and the functions were more depended on the plexus (North et al. 1985, Xia et al. 2000).

A common way to study the sympathetic contribution to regulatory responses is through the use of sympathectomy. The catecholamine-depleting effect of reserpine is caused by an irreversible blockage of the catecholamine storage mechanism in the amine storage granules of catecholamine-containing cells (MartínezOlivares et al. 2006), producing a nonspecific temporary sympathectomy (Fleming et al. 1973). When the endogenous catecholamine was depleted by reserpine, the basic $I_{\mathrm{sc}}$ in the colorectal mucosa was much greater than that in controls, suggesting that the loss of sympathetic control is able to enhance the baseline mucosal secretion. Both sympathetic and parasympathetic systems play an important role in the regulation of the balance of intestinal secretion. After reserpine-sympathetomy, parasympathetic dominance play uncompetitive role in the intestinal basic secretion, abolishing net sodium movement and inducing net chloride secretion (Keely et al. 2011). Furthermore, the exogenous NE induced $I_{\mathrm{sc}}$ increase is related to the up-regulated $\beta$ receptors (mainly $\beta_{2}$-adrenoceptors) and down-regulated NET, which is an adapted response to the depletion of endogenous catecholamine. Because the mRNA levels are not always consistent with the protein levels, the low mRNA levels of $\beta$-adrenoceptors might be the consequence of a negative feedback regulatory mechanism (Tian et al. 2008) or a direct influence on the transcription and halflife of the mRNA (Bergann et al. 2009).

NET is a 12-transmembrane protein and a member of the $\mathrm{Na} / \mathrm{Cl}$-dependent monoamine transporters, and it is localized presynaptically on noradrenergic nerve terminals. Reuptake of released NE by NET in the synapse is the major physiological mechanism by which released NE is inactivated (Barker and Blakely 1995). Sympathetic neurons are a prominent source of NET, and their axons project to the gut; therefore, NET functionality has a strong role in dictating the distribution of sympathetic innervation (Mayer et al. 2006). It has been reported that no significant difference exists in the NET mRNA level across any specific region of normal mouse bowel, from the stomach to distal colon and rectum ( $\mathrm{Li}$ et al. 2010). In the present study, reserpine-induced catecholamine depletion not only exhausted the endogenous $\mathrm{NE}$ but also reduced the expression of NET in the colorectum of the rat. This is different from what we observed with the adrenergic receptors. On one hand, the limited NE reuptake may have directly led to the down-regulation of NET; on the other hand, to maintain the NE concentration in the synaptic space, the down-regulation of NET may have been an adaptive alteration. All the above reflect a weak sympathetic innervation on the colorectal mucosa.

Abnormalities of the autonomic nervous system have been associated with several disease processes of the colon and rectum. The colorectum is the vulnerable part in inflammatory bowel diseases such as colorectal inflammation, ulcers and even tumors, and $\beta$-adrenoceptors localized here can play an important role in the trans-epithelial ion transport in physiological and pathophysiological conditions that alter catecholamine levels (Zhang et al. 2010). Decreased colonic NE release was found in inflammatory bowel disease (IBD) and Crohn's disease (Swain et al. 1991, Straub et al. 2006). However, in ulcerative colitis, the density of the 
adrenergic nerve fibers and sympathetic activities was significantly increased (Kyosola et al. 1977, Furlan et al. 2006). Although the dysfunction of the sympathetic nervous system is not the causative agent in these intestinal diseases, it contributes to some clinical symptoms. It is reported that inflammation-induced inhibition of NE release could reduce the sympathetic repression of secretomotor neurons, which leads to a state of neurogenic secretory diarrhea (Straub et al. 2006). In our study, almost all of the catecholamine-depleted rats had a shapeless stool. The possible reasons might be the enhanced basic mucosal secretion, which was caused by loss of sympathetic control and a predominant parasympathetic activity. Of course, the diarrhea in catecholamine-depleted rats was not just due to the abnormal regulation of basal ion transport in the mucosa. It has been reported that sympathetic nervous system also takes part in the colonic motility (Ridolfi et al. 2009) and immune regulation (Straub et al. 2006, Cervi et al. 2013), therefore these influence should not be ignored.

In summary, the sympathetic nervous system plays an important role in regulating ion transport in the colorectum. Disruption of sympathetic neurotransmitters resulted in abnormal ion transport and both $\beta$-adrenoceptor and NET were involved in the process.

\section{Conflict of Interest}

There is no conflict of interest.

\section{Acknowledgements}

This study was financially supported by grants from the National Natural Science Foundation of China (81170346, 31300954), the National Science and Technology Major Project (2012ZX10004904-003-001).

\section{References}

BARKER E, BLAKELY R: Norepinephrine and serotonin transporters: molecular targets of antidepressant drugs. In: Psychopharmacology: the Fourth Generation of Progress. BLOOM F, KUPFER D (eds), Raven Press, New York, 1995, pp 321-333.

BERGANN T, ZEISSIG S, FROMM A, RICHTER JF, FROMM M, SCHULZKE JD: Glucocorticoids and tumor necrosis factor-alpha synergize to induce absorption by the epithelial sodium channel in the colon. Gastroenterology 136: 933-942, 2009.

CAREY HV, ZAFIROVA M: Adrenergic inhibition of neurally evoked secretion in ground squirrel intestine. Eur $J$ Pharmacol 181: 43-50, 1990.

CERVI AL, LUKEWICH MK, LOMAX AE: Neural regulation of gastrointestinal inflammation: role of the sympathetic nervous system. Auton Neurosci 182: 83-88, 2014.

FAN Y, HUANG JJ, KIERAN N, ZHU MY: Effects of transcription factors Phox2 on expression of norepinephrine transporter and dopamine $\beta$-hydroxylase in SK-N-BE(2)C cells. J Neurochem 110: 1502-1513, 2009.

FLEMING WW, MCPHILLIPS J, WESTFALL DP: Postjunctional supersensitivity and subsensitivity of excitable tissues to drugs. Ergeb Physiol 68: 55-119, 1973.

FURLAN R, ARDIZZONE S, PALAZZOLO L, RIMOLDI A, PEREGO F, BARBIC F, BEVILACQUA M, VAGO L, BIANCHI PG, MALLIANI A: Sympathetic overactivity in active ulcerative colitis: effects of clonidine. Am J Physiol Regul Integr Comp Physiol 290: R224-R232, 2006.

GERSHON MD, ERDE SM: The nervous system of the gut. Gastroenterology 80: 1571-1594, 1981.

KEELY SJ: Epithelial acetylcholine - a new paradigm for cholinergic regulation of intestinal fluid and electrolyte transport. J Physiol 589: 771-772, 2011.

KUNZELMANN K, MALL M: Electrolyte transport in the mammalian colon: mechanisms and implications for disease. Physiol Rev 82: 245-289, 2002.

KYOSOLA K, PENTTILA O, SALASPURO M: Rectal mucosal adrenergic innervation and enterochromaffin cells in ulcerative colitis and irritable colon. Scand J Gastroenterol 12: 363-367, 1977.

LAM RS, APP EM, NAHIRNEY D, SZKOTAK AJ, VIEIRA-COELHO MA, KING M, DUSZYK M: Regulation of Cl- secretion by alpha2-adrenergic receptors in mouse colonic epithelium. J Physiol 548: 475-484, 2003.

LI Z, CARON MG, BLAKELY RD, MARGOLIS KG, GERSHON MD: Dependence of serotonergic and other nonadrenergic enteric neurons on norepinephrine transporter expression. J Neurosci 30: 16730-16740, 2010. 
LIU L, COUPAR IM: Role of alpha 2-adrenoceptors in the regulation of intestinal water transport. Br J Pharmacol 120: 892-898, 1997.

MARTÍNEZ-OLIVARES R, VILLANUEVA I, RACOTTA R, PIÑÓN M: Depletion and recovery of catecholamines in several organs of rats treated with reserpine. Auton Neurosci 128: 64-69, 2006.

MATTHIES HJ, HAN Q, SHIELDS A, WRIGHT J, MOORE JL, WINDER DG, GALLI A, BLAKELY RD: Subcellular localization of the antidepressant-sensitive norepinephrine transporter. BMC Neurosci 10: 65, 2009.

MAYER AF, SCHROEDER C, HEUSSER K, TANK J, DIEDRICH A, SCHMIEDER RE, LUFT FC, JORDAN J: Influences of norepinephrine transporter function on the distribution of sympathetic activity in humans. Hypertension 48: 120-126, 2006.

NORTH RA, SURPRENANT A: Inhibitory synaptic potentials resulting from alpha 2-adrenoceptor activation in guinea-pig submucous plexus neurones. $J$ Physiol 358: 17-33, 1985.

RIDOLFI JT, TONG WD, TAKAHASHI T, KOSINSKI L, LUDWIG AK: Sympathetic and parasympathetic regulation of rectal motility in rats. J Gastrointest Surg 13: 2027-2033, 2009.

SCHULTHEISS G, DIENER M: Adrenoceptor-mediated secretion across the rat colonic epithelium. Eur J Pharmacol 403: 251-258, 2000.

STRAUB RH, WIEST R, STRAUCH UG, HÄRLE P, SCHÖLMERICH J: The role of the sympathetic nervous system in intestinal inflammation. Gut 55: 1640-1649, 2006.

SWAIN MG, BLENNERHASSETT PA, COLLINS SM: Impaired sympathetic nerve function in the inflamed rat intestine. Gastroenterology 100: 675-682, 1991.

TAPPER EJ, BROON AS, LEWAND DL: Endogenous norepinephrine release induced by tyramine modulates intestinal ion transport. Am J Physiol 241: G264-G269, 1981.

TIAN YM, CHEN X, LUO DZ, ZHANG XH, XUE H, ZHENG LF, YANG N, ZHU JX: Alteration of dopaminergic markers in Ggastrointestinal tract of different rodent models of Parkinson's disease. Neuroscience 153: 634-644, 2008.

VANNER S, SURPRENANT A: Neural reflexes controlling intestinal microcirculation. Am J Physiol 271: G223-G230, 1996.

WINGE K, RASMUSSEN D, WERDELIN LM: Constipation in neurological diseases. J Neuorsurg Psychiatry 74: 13-19, 2003.

XIA Y, HU HZ, LIU S, POTHOULAKIS C, WOOD JD: Clostridium difficile toxin A excites enteric neurones and suppresses sympathetic neurotransmission in the guinea pig. Gut 46: 481-486, 2000.

ZHANG XH, ZHANG XF, ZHANG JQ, TIAN YM, XUE H, YANG N, ZHU JX: $\beta$-adrenoceptors, but not dopamine receptors, mediate dopamine-induced ion transport in late distal colon of rats. Cell Tissue Res 334: 25-35, 2008.

ZHANG XH, JI T, GUO H, LIU SM, LI Y, ZHENG LF, ZHANG XF, ZHANG Y, DUAN ZP, ZHU JX: Expression and activation of $\beta$-adrenoceptors in colorectal mucosa of rat and human. Neurogastroenterol Motil 22: e325-e334, 2010. 